\title{
Risk Factors of Antepartum Hemorrhage Among Mothers Who Gave Birth at Suhul General Hospital, 2016: A Case-Control Study
}

This article was published in the following Dove Press journal: Journal of Multidisciplinary Healthcare

\section{Bekem Dibaba $\mathbb{D}^{\prime}$ \\ Dejene Edosa' \\ Mohammedamin Hajure (D) ${ }^{2}$ Gelawdiwos Gebre ${ }^{3}$}

'Midwifery Department, Public Health and Medical Sciences, Mettu University, Mettu, Ethiopia; ${ }^{2}$ Psychiatry Department, Public Health and Medical Sciences, Mettu University, Mettu, Ethiopia; ${ }^{3}$ Midwifery Department, Public Health and Medical Sciences, Mekele University, Mekele, Ethiopia
Correspondence: Bekem Dibaba Email bekilo20I8@gmail.com
Background: Antepartum hemorrhage is a very serious problem and contributes significantly to maternal and neonatal morbidity and mortality in developing countries including Ethiopia. Identification of risk factors of antepartum hemorrhage will help for prevention and control programs.

Methods: An institutional-based case-control study was conducted from July 2013 to June 2016. A simple random sampling technique was employed, and 420 mothers' medical cards were reviewed using a pretested checklist. The data were entered in to EPI-info version 7 and then exported to SPSS version 20 for analysis, and all variables with a $P$-value $<0.2$ at bivariate logistic regression analysis were considered as a candidate for multivariate logistic regression analysis, and those variables with a $P$-value $<0.05$ in multiple logistic regression analysis were considered as significantly associated at $95 \%$ confidence interval.

Results: Results of the multiple logistic regression showed that those mothers whose age was in the range of 35-44 years were significantly 4-times more likely to present with antepartum hemorrhage as compared to mothers in the age range of 15-24 years. Moreover, mothers who presented with a previous history of cesarean section were 4.7-times more likely to present with antepartum hemorrhage than those who had no previous history of cesarean section. Furthermore, women with a previous history of abortion were 2-times more likely to develop antepartum hemorrhage as compared to women who had no previous history of abortion.

Conclusion and Recommendation: In this study, the factors found to be risk factors of antepartum hemorrhage were maternal age, previous history of cesarean section, and previous history of abortion. Strategies towards reduction of unwanted pregnancy to prevent abortion, pregnancy at advanced age, and to reduce the cesarean section rate should be emphasized.

Keywords: antepartum hemorrhage, risk factors, Suhul, Tigrai, Ethiopia, 2016

\section{Introduction}

Antepartum hemorrhage (APH) is one of the leading causes of obstetrical hemorrhage and maternal death and also a major cause of perinatal morbidity and mortality worldwide. A study conducted at Medical College, Mysore, India showed that, in spite of a lot of improvement in the form of antenatal care and intrapartum surveillance, antepartum hemorrhage has not reduced. It still continues to constitute a major portion of obstetrical hemorrhage. ${ }^{1}$

Antepartum hemorrhage (APH) is very serious and one of the most frequent obstetrical emergencies, and is the most common preventable cause of maternal death, responsible for $25-60 \%$ of maternal mortality. Antepartum hemorrhage occurs 
without warning signs. Thus there is a need to identify the risk factors associated with antepartum hemorrhage to help obstetricians in the early diagnosis and treatment. These risk factors include previous APH, previous cesarean section, advanced maternal age (age greater than 35), urban/rural residence, previous termination of pregnancy (curettage), pregnancy-induced hypertension (PIH), multi-parity, and multiple pregnancy. ${ }^{2}$

In developing countries like India, women frequently experience adverse effects of obstetric hemorrhage due to widespread pre-existing anemia, difficulties with transport, and overwhelming inadequacies of maternity services. ${ }^{3}$

A case-control study conducted in Nigeria showed that the main causes of antepartum hemorrhage were placenta previa $(55.6 \%)$, abruption placenta $(33.3 \%)$, and unknown cause $(8.4 \%)$. Antepartum hemorrhage contributes significantly to maternal and neonatal morbidity and mortality in sub-Saharan Africa. ${ }^{4}$

Antepartum hemorrhage could be prevented by early registration, regular antenatal care, early detection of high risk cases, and early referral to a higher center. Good facilities for cesarean section, availability of blood banks, and use of contraceptives can improve maternal and perinatal outcome of $\mathrm{APH}^{5}$

A study conducted at Jimma university specialized hospital revealed that APH, primarily caused by abruption placenta and placenta previa, is a common complication of pregnancy and cause of maternal and perinatal mortality. The risk of adverse maternal and newborn outcomes including maternal mortality, perinatal mortality, and low birth weight is higher among APH cases in Jimma University Specialized Hospital compared to reports from other countries. Efforts to improve geographical access, referral services, and quality of comprehensive emergency obstetric care are needed to improve maternal and newborn outcomes in Ethiopia. ${ }^{6}$

Vaginal bleeding after mid-pregnancy is associated with maternal and fetal risks. Maternal morbidity may be caused by acute hemorrhage and operative delivery, and the fetus may be compromised by uteroplacental insufficiency and premature birth. ${ }^{7}$

More than $99 \%$ of all maternal deaths occur in the developing world and the great majority of these are avoidable. Women continue to die unnecessarily in pregnancy and childbirth in these countries due to obstetrics complications, specifically APH. If we are serious about stopping these unnecessary maternal deaths, with the proper resources and implementation we can build a future for these communities. APH, irrespective of cause, increases prenatal morbidity and mortality, hence the condition demands full investigation and careful management. ${ }^{8}$

Effective management of vaginal bleeding in late pregnancy requires recognition of potentially serious conditions, accurate and timely identification of the cause of bleeding, the team system or approach, which optimizes women's safety, and well-timed intervention specific to diagnosis. ${ }^{9}$

Women with a history of APH are at increased risk for adverse perinatal outcomes including small for gestational age and growth restricted fetuses, therefore initiation of serial ultrasounds is recommended. ${ }^{10}$

This study, conducted at Jimma University specialized hospital, focused only on adverse maternal and newborn outcomes of abruption placenta and placenta previa and complications of APH rather than finding the risk factors contributing to APH, which is very important to identify the mothers at high risk to develop antepartum hemorrhage.

\section{Objective}

The objective of this study was to identify the risk factors of antepartum hemorrhage among women who gave birth at Suhul general hospital during the period of 2013-2016, north western Tigray: A case-control study.

\section{Methods and Materials}

\section{Study Area and Period}

The study was conducted at Suhul Hospital from JuneJuly 2016 which is a general public hospital located in Shire Endasselassie town situated 301 kilometers from Mekelle and 1,087 kilometers from Addis Ababa in the North Western part of Tigray region in Ethiopia.

\section{Study Design}

An institutional-based case-control study was conducted.

\section{Source Population}

All cards of mothers who gave birth at Suhul general hospital. Cases: All cards of delivered mothers who developed APH during the period of 2013-2016. Controls: All cards of delivered mothers who did not developed APH during the period of 2013-2016.

\section{Study Population}

Cases: Randomly selected cards of delivered mothers who developed APH during the period of 2013-2016.

Controls: Randomly selected cards of delivered mothers who did not develop APH during the period of 2013-2016. 


\section{Eligibility Criteria}

Inclusion and Exclusion Criteria

All mothers' cards that contain full information needed for the study (the card which contains all variables used in the study) were included. Mothers who were registered on the log book but whose cards were missed and mother's card with an unknown gestational age were excluded.

\section{Sample Size Calculation, Techniques, and Procedures} Sample size was determined by two population proportions by EPI-info version 7 using 95\% CI, 80\% power, and sn odds ratio of 2.443 taken from a study conducted at Ladoke Akintola University of Technology (LAUTECH) Teaching Hospital, southwestern Nigeria, which shows that un-booked mothers were significantly more likely to present with antepartum hemorrhage, $\quad 66.7 \% \quad(\mathrm{OR}=2.443, \quad 95 \%$ $\mathrm{CI}=1.030-5.794)$, and in the control exposed group those significantly at higher risk of having antepartum hemorrhage were $42.9 \%(\mathrm{OR}=2.443,95 \% \mathrm{CI}=1.030-5.794)$, a 1:2 ratio of cases to controls. Accordingly the total of 420 cards, 140 cases, and 280 controls were included in the study.

The card numbers of both cases and controls were identified from a egistration book of those registered during the past 3 years, from July 2013 to June 2016. Accordingly 317 cases and 5,343 controls were identified. All cards were reviewed to check their completeness with information needed in the study. Mothers' cards with APH (cases) which fulfilled the inclusion criteria used for their completeness were 283, 29 cards were incomplete, and five cards were missed and were excluded. Similarly the cards of the control group were checked for their completeness and 4,821 cards were complete and 522 cards excluded (503 cards for their incompleteness and 19 cards were missed). Then 283 cards of cases and 4,821 cards of controls were coded and entered into SPSS version 20 to select cards included in the study randomly (by computer generated simple random sampling).

\section{Data Collection Procedure, Period, and Quality Control}

The data was collected from August 1 to September 30, 2016 using mothers' clinical records by a structured data collecting checklist which was developed from different literature. This structured checklist was prepared in English and tested before the actual data collection. The data was collected by two midwives who were oriented for 1 day before data collection on the proper application of the data collection tool. Data quality was ensured during data collection, coding, entry, and analysis. A pre-tested structured checklist was used. Orientation was given for the data collectors to prevent any confusion and have a common understanding about the study, provision of full information, and appropriate documentation. Supervision of data collectors included observation of how the data collectors collect data, and was done by the principal investigator.

\section{Study Variables}

Dependent variable: Antepartum hemorrhage.

Independent variables: Socio demographic characteristics (Maternal age, Residence).

Obstetrics characteristics during admission: Antenatal care, Pregnancy induced hypertension, Parity, Number of fetuses, Polyhydramnios, Amniocentesis, Macrosomia, Premature Rapture of Membrane, Chorioamnits, early pregnancy vaginal bleeding, Accident Trauma.

Previous obstetrics history: previous history of antepartum hemorrhage, prior cesarean section, previous termination of pregnancy curettage, previous pregnancy induced hypertension.

\section{Data Analysis and Management}

Data were coded and entered to EPI Info version 7, then exported to SPSS version 20 for analysis. Both descriptive and analytical statistical procedures were utilized. Descriptive statistics like percentage, mean and standard deviation were used for the presentation of demographic data and obstetrics factors. Tables and graphs were also used for data presentation.

Binary logistic regression was used to identify factors associated with antepartum hemorrhage. Associations between antepartum hemorrhage and socio-demographic and obstetrics factors were explored using bivariate and multivariate logistic regression. Multivariate logistic regression analysis was applied to investigate associated factors through stepwise adjustment. The variables were entered into the multivariate model using the forward Stepwise regression method.

All variables with a $P$-value $<0.2$ at bivariate logistic regression analysis were considered as a candidate for multiple logistic regression analysis and those variables with a $P$-value $<0.05$ in multiple logistic regression analysis were considered as significantly associated factors with antepartum hemorrhage. The degree of association between independent and dependent variables was assessed using an odds ratio with $95 \%$ confidence interval. 


\section{Operational Definition}

Antepartum hemorrhage: Antepartum hemorrhage (APH) is defined as bleeding from or into the genital tract, occurring from 28 weeks of pregnancy and prior to the birth of the baby.

Card with incomplete information: Card which had no full information about mother's pregnancy condition and past obstetric history (when one or more variables used in the study were missed).

Missed Card: Mother's medical card which was not available on the shelf of the card room during the data collection period.

Unknown gestational age: No written gestational age on mother's medical card because the mother did not remember her last menstrual period to calculate gestational age.

\section{Results}

Socio-Demographic Characteristics of Mothers Who Gave Birth at Suhul General Hospital Who Had APH and Had No APH During the Period of 2013-2016

The mean (SD) age among the cases was $29.76( \pm 7.19)$ years (range $=17-44$ ), and among the controls was 27.55 ( \pm 6.28 ) years (range=17-44). Most of the women who presented with antepartum hemorrhage (cases) (78, $55.7 \%$ ) were from out of Shire town and the remaining were from Shire town; and from the control group, 166 (59.3\%) were living in Shire town and 114 (40.7\%) were living out of Shire (Table 1).

Table I Socio-Demographic Characteristics of Mothers Who Gave Birth at Suhul General Hospital Who Had APH and Had No APH During the Period of 2013-2016 ( $n=420)$

\begin{tabular}{|c|c|c|c|}
\hline Characteristics & $\begin{array}{l}\text { Case } \\
(n=\mid 40) \\
(\%)\end{array}$ & $\begin{array}{l}\text { Controls } \\
(n=280)(\%)\end{array}$ & $\begin{array}{l}\text { Total } \\
(n=420)(\%)\end{array}$ \\
\hline \multicolumn{4}{|l|}{ Age in years } \\
\hline $15-24$ & 44 (3I.4\%) & 105 (37.5\%) & 149 (35.5\%) \\
\hline $25-34$ & 36 (25.7\%) & 148 (52.9\%) & I 84 (43.8\%) \\
\hline $35-44$ & 60 (42.9\%) & 27 (9.6\%) & 87 (20.7\%) \\
\hline Mean \pm SD & $29.76 \pm 7.19$ & $27 \pm 5.55$ & $27.9 \pm 6.28$ \\
\hline \multicolumn{4}{|l|}{ Residence } \\
\hline I. Shire & 62 (44.3\%) & 166 (59.3\%) & 228 (54.3\%) \\
\hline 2. Out of Shire & 78 (55.7\%) & II 4 (40.7\%) & 192 (45.7\%) \\
\hline
\end{tabular}

\section{Obstetrics Characteristics of Mothers Who Gave Birth at Suhul General Hospital Who Had APH and Had No APH During the Period of 2013-2016}

Among women who had antepartum hemorrhage (cases), 58 (41.43\%), and among controls, 49 (17.5\%) were grand multiparous. Among the study subjects, the majority of both cases and controls had ANC follow-up; 133 (95\%) of cases and 266 (95\%) of controls.

Among the study subjects, 67 (49.9\%) of the cases and $60(21.6 \%)$ of the controls were diagnosed by ultrasonography during their ANC follow-up. The number of women with antepartum hemorrhage (cases) and controls that developed vaginal bleeding during early pregnancy were $14(10 \%)$ and $11(3.9 \%)$, respectively.

Among mothers presented with antepartum hemorrhage (cases), six (4.3\%) presented with blunt abdominal trauma, as did four $(1.4 \%)$ of the controls.

Among the study subjects, 10 (7.1\%) mothers with APH (cases) and 18 (6.4\%) controls had premature rapture of membrane (PROM) during their admission, of which five (3.6\%) $\mathrm{f}$ cases and nine (3.2\%) controls had chorioamnionitis.

Regarding the number of fetuses, from the cases, 130 (92.9\%) were singletons, 10 (7.1\%), twins and from control group, 263 (93.9\%) were singletons, 16 (5.7\%) twins, and one $(0.4 \%)$ was triplets.

REgarding pregnancy related disorders, 15 (10.7\%) mothers with APH and 36 (12.9\%) of the control group presented with pregnancy induced hypertension, and six (4.3\%) cases and $12(4.3 \%)$ of controls were diagnosed with polyhydramnios, from which only one $(0.7 \%)$ of the cases and two $(0.7 \%)$ of the controls were managed with amniocentesis.

Among the study subjects, $67(49.9 \%)$ cases and 60 $(21.6 \%)$ controls were diagnosed by ultrasonography during their ANC follow-up, and three (2.1\%) women with APH and five (1.8\%) controls were diagnosed with macrosomia. Among mothers with APH (cases), 76 (54.3\%), and mothers without APH (controls), 26 (9.3\%) were delivered at gestational age of $<37$ weeks (preterm birth) (Table 2).

Previous Obstetrics Characteristics of Mothers Who Gave Birth at Suhul General Hospital Who Had APH and Had No APH During the Period of 2013-2016

Concerning other pre-existing maternal health problems, 11 (9.1\%) mothers presented with APH (cases) and 27 (11.2\%) 
Table 2 Obstetric Characteristics of Mothers Who Gave Birth at Suhul General Hospital Who Had APH and Had No APH at Admission During the Period of 2013-2016

\begin{tabular}{|c|c|c|c|c|c|}
\hline Variables & Cases & Controls & Variables & Cases & Controls \\
\hline Parity & & & Number of fetuses & & \\
\hline I. Nulliparous & 12 (8.57\%) & 40 (14.28\%) & Single & 130 (92.9\%) & 263 (93.9\%) \\
\hline 2. Primiparous & $26(18.57 \%)$ & $82(29.3 \%)$ & Twin & $10(7.1 \%)$ & $16(5.7 \%)$ \\
\hline 3. Multiparous & 44 (31.43\%) & 109 (38.9\%) & Triplet & 0 & I (0.4\%) \\
\hline 4. Grandmultipara & $58(41.43 \%)$ & 49 (I7.5\%) & Polyhydramnios & & \\
\hline Gestational age & & & No & $134(95.7 \%)$ & $268(95.7 \%)$ \\
\hline Preterm & 76 (54.3\%) & $26(9.3 \%)$ & Yes & $6(4.3 \%)$ & $12(4.3 \%)$ \\
\hline Term & $57(40.7 \%)$ & 227 (81.1\%) & Amniocentesis & & \\
\hline Post-term & 7 (5\%) & 27 (9.6\%) & No & 139 (99.3\%) & 278 (99.3\%) \\
\hline ANC follow-up & & & Yes & I (0.7\%) & $2(0.7 \%)$ \\
\hline No & $7(5 \%)$ & $14(5 \%)$ & & & \\
\hline Yes & 133 (95\%) & $266(95 \%)$ & Macrosomia & & \\
\hline Early pregnancy vaginal bleeding & & & No & 137 (98.7\%) & $275(98.2 \%)$ \\
\hline No & $126(90 \%)$ & $269(96.1 \%)$ & Yes & $3(2.1 \%)$ & $5(1.8 \%)$ \\
\hline Yes & $14(10 \%)$ & II (3.9\%) & Ultrasonography on ANC follow-up & & \\
\hline Abd. trauma & & & No & $73(52.1 \%)$ & $220(78.4 \%)$ \\
\hline No & 134 (95.7\%) & $276(98.6 \%)$ & Yes & 67 (49.9\%) & $60(21.6 \%)$ \\
\hline Yes & $6(4.3 \%)$ & $4(1.4 \%)$ & & & \\
\hline PROM & & & PIH & & \\
\hline No & I 30 (92.9\%) & $262(93.6 \%)$ & No & $125(89.3 \%)$ & $244(87.1 \%)$ \\
\hline Yes & $10(7.1 \%)$ & $18(6.4 \%)$ & Yes & $15(10.7 \%)$ & $36(12.9 \%)$ \\
\hline \multicolumn{6}{|l|}{ Chorioamnitis } \\
\hline No & 135 (96.4\%) & $271(96.8)$ & & & \\
\hline Yes & $5(3.6 \%)$ & 9 (3.2\%) & & & \\
\hline
\end{tabular}

mothers who were presented without APH (controls) complained of a previous history of pregnancy induced hypertension and $10(8.3 \%)$ cases and $18(7.5 \%)$ controls had a history of antepartum hemorrhage previously.

This study also demonstrated that $36(25.7 \%)$ of the cases and $47(16.8 \%)$ controls experienced previous history of abortion. Thirty-five (28.9\%) mothers with APH and $20(8.3 \%)$ of the controls had a history of previous cesarean section (see Table 3).
Logistic Regression Analysis of Factors Associated with APH Among Mothers Who Gave Birth at Suhul General Hospital Who Had APH and Had No APH During the Period of 2013-2016

Variables considered for multiple logistic regression were those with a $P$-value $<0.2$ at bivariate logistic regression analysis and these included age, residence, previous 
Table 3 Previous History of Obstetrics Characteristics of Mothers Who Gave Birth at Suhul General Hospital Who Had APH and Had No APH During the Period of 2013-2016

\begin{tabular}{|c|c|c|}
\hline Variables & Cases & Controls \\
\hline \multicolumn{3}{|l|}{ History of APH $(n=362)$} \\
\hline No & III (91.7\%) & $223(92.5 \%)$ \\
\hline Yes & $10(8.3 \%)$ & $18(7.5 \%)$ \\
\hline \multicolumn{3}{|l|}{ History of PIH $(n=362)$} \\
\hline No & 110 (90.9\%) & $214(88.8 \%)$ \\
\hline Yes & II (9.1\%) & $27(11.2 \%)$ \\
\hline \multicolumn{3}{|l|}{ History of abortion $(n=420)$} \\
\hline No & 104 (74.3\%) & $233(83.2 \%)$ \\
\hline Yes & $36(25.7 \%)$ & $47(16.8 \%)$ \\
\hline \multicolumn{3}{|l|}{ History of previous cesarean section $(n=362)$} \\
\hline No & $86(71.1 \%)$ & 221 (91.7\%) \\
\hline Yes & $35(28.9 \%)$ & $20(8.3 \%)$ \\
\hline
\end{tabular}

history of abortion, parity, early pregnancy vaginal bleeding, and history of previous cesarean section.

During multiple logistic regression, advanced maternal age, previous history of abortion, and previous history of cesarean section delivery were significant risk factors for antepartum hemorrhage (Table 4).

\section{Discussion}

The finding of this study indicated that risk factors found to be associated with antepartum hemorrhage were advanced maternal age ( $\geq 35$ years) $(A O R=4.00,95 \%$ $\mathrm{CI}=1.48-11.12$ ), a history of previous cesarean section $(\mathrm{AOR}=4.70,95 \% \mathrm{CI}=2.29-9.69)$, and a history of previous abortion $(\mathrm{AOR}=2.00,95 \% \mathrm{CI}=1.08-3.46)$.

Results of the multiple logistic regression in this study showed that those mothers whose age was in the range of 35-44 years were significantly 4-times more likely to present with antepartum hemorrhage as compared to mothers in the age range of 15-24 years.

This is in agreement with studies done in India (Maharashtra \& Medical College of Jodhpur), Nigeria, Iran, and Pakistan, which revealed that maternal age over 35 years was found to be a risk factor for antepartum hemorrhage. ${ }^{3,7,11,12}$ This is due to the fact that older maternal age may show an association with increased obstetric

Table 4 Bivariate and Multivariate Analysis of Factors Associated with APH of Factors Associated with APH Among Mothers Who Gave Birth at Suhul General Hospital Who Had APH and Had No APH During the Period of 20I3-2016

\begin{tabular}{|c|c|c|c|c|}
\hline Variables & Cases $(n=\mid 40)(\%)$ & Controls $(n=280)(\%)$ & COR $(95 \% \mathrm{Cl})$ & AOR (95\% Cl) \\
\hline \multicolumn{5}{|l|}{ Age in years } \\
\hline 15-24 & $44(31.4 \%)$ & $105(37.5 \%)$ & 1 & I \\
\hline $25-34$ & $36(25.7 \%)$ & I 48 (52.9\%) & $0.58(0.37-1.03)$ & $0.50(0.24-1.04)$ \\
\hline $35-44$ & 60 (42.9\%) & 27 (9.6\%) & $5.30(3.08-9.75)$ & $4(1.48-11.12) *$ \\
\hline \multicolumn{5}{|l|}{ Residence } \\
\hline I. Shire & $62(44.3 \%)$ & $166(59.3 \%)$ & 1 & I \\
\hline 2. Out of Shire & 78 (55.7\%) & II 4 (40.7\%) & I.83 $(0.36-0.82)$ & $1.19(0.69-2.03)$ \\
\hline \multicolumn{5}{|l|}{ Early Px Vx bleeding } \\
\hline No & $126(90 \%)$ & $269(96.1 \%)$ & 1 & I \\
\hline Yes & $14(10 \%)$ & II (3.9\%) & $2.72(1.2-6.15)$ & $2.03(0.67-6.10)$ \\
\hline \multicolumn{5}{|l|}{ Parity } \\
\hline Nulliparous & $12(8.57 \%)$ & $40(14.28 \%)$ & I & I \\
\hline Primiparous & $26(18.57 \%)$ & $82(29.3 \%)$ & $1.06(0.48-2.30)$ & $0.37(0.0 \mathrm{I}-9.8 \mathrm{I})$ \\
\hline Multiparous & $44(31.43 \%)$ & 109 (38.9\%) & $1.35(0.65-2.80)$ & $0.39 \mid(0.02-10.4 \mid)$ \\
\hline Grand-multiparous & $58(41.43 \%)$ & $49(17.5 \%)$ & $3.95(1.89-8.34)$ & $0.44(0.02-|2.4|)$ \\
\hline \multicolumn{5}{|l|}{ History of abortion } \\
\hline No & $104(74.3 \%)$ & $233(83.2 \%)$ & 1 & I \\
\hline Yes & $36(25.7 \%)$ & $47(16.8 \%)$ & $1.72(1.5 I-3.89)$ & $2(1.08-3.46)^{*}$ \\
\hline \multicolumn{5}{|l|}{ History of $C / S(n=362)$} \\
\hline No & 86 (7I.I\%) & 221 (91.7\%) & 1 & I \\
\hline Yes & 35 (28.9\%) & 20 (8.3\%) & $4.5(2.46-8.22)$ & $4.7(2.29-9.69)^{*}$ \\
\hline
\end{tabular}

Note: *Significant variables during multiple logistic regression analysis. 
complications which may be secondary to reduced cardiovascular reserve, relatively high incidence of underlying medical disease, and also decreased ability to respond and adapt to the physical stress that accompanies aging. It also could be due to sclerotic changes on intra-myometrium arteries increases with increasing age, thereby reducing the blood supply to the placenta. $2,3,7,11,12$

Another risk factor of APH in this study was a previous history of cesarean section. Mothers who presented with previous history of cesarean section were 4.7-times more likely to present with antepartum hemorrhage than those who had no previous history of cesarean section.

This is comparable to the study in Grant Medical College and Sir JJ Group of Hospitals \& Medical College, Jodhpur, India \& Iran which has recently shown that the uterine scar of cesarean section prevented migration of the placenta during the course of pregnancy toward the more vascularized uterine fundus. Risk of placenta previa is highest in the pregnancy immediately following cesarean section. Failure of appropriate lower segment devolvement, because of scar tissue, could be a cause and raw area favorable for implantation. Incidence of placenta previa increases in a linear way with increasing number of previous cesarean sections. ${ }^{2,6,12}$

The findings of this study also confirmed another risk factor found to be associated with antepartum hemorrhage was previous history of abortion. This indicated that women with a previous history of abortion were 2-times more likely to develop APH as compared to women who had no previous history of abortion.

This is comparable to a studies conducted in Iran, Pakistan, and Sweden. ${ }^{11,12,13}$ The mechanism of how previous abortions predispose to APH development could be explained with possible endometrial damage during repeated abortions, which impedes successful fundal implantation of placenta. ${ }^{11,12,13}$

\section{Limitations}

The limitation of this study was the challenge to get adequate information concerning some variables. Using secondary data limits the study variables of sociodemographic characteristics such as religion, ethnicity, educational status, income, and occupation.

\section{Conclusion}

The finding of this study indicated that risk factors found to be associated with antepartum hemorrhage were advanced maternal age, previous history of abortion, and previous history of cesarean section.

\section{Abbreviations}

AOR, adjusted odds ratio; APH, antepartum hemorrhage; $\mathrm{ANC}$, antenatal care; $\mathrm{CI}$, confidence interval; CS, cesarean section; OR, odds ratio; PROM, premature rapture of membrane; SPSS, Statistical Package for Social Science.

\section{Data Sharing Statement}

Data sets used and examined in this study are obtainable from the corresponding author upon sound request.

\section{Ethics Approval and Consent to Participate}

The study was conducted following the 2013 revised Declaration of Helsinki and ethical clearance was gained from the ethical review committee of Mekele University, faculty of health and medical sciences. A letter of permission was obtained from the Midwifery department. Participants were communicated with about the purpose, risk, and benefits of the study and were invited to participate. Confidentiality was kept utmost and all related queries were responded to, and they provided written informed consent for participation.

\section{Acknowledgments}

The authors are grateful to Mekele University for providing ethical permission to undertake this study.

\section{Funding}

Ethiopian ministry of Education funded this study.

\section{Disclosure}

The authors state that they have no competing interests, financial or otherwise.

\section{References}

1. Nagapurkar S, Tale A, Ranjwan B. Risk factors for ante partum hemorrhage: a hospital based study. Int J Recent Trends Sci Technol. 2015;15(2):2277-2812.

2. Bhandiwad A, Abhishek A, Fadero B. Ante-partum hemorrhage and pregnancy outcome in LAUTECH Teaching Hospital, southwestern Nigeria. J Med Med Sci. 2011;2(12):1243-1247.

3. Naiknaware SV. Antepartum hemorrhage: causes \& its effects on mother and child: an evaluation. Obstet Gynecol Int J. 2015;3(1).

4. Bhandiwad A, Bhandiwad AA. A study of maternal and fetal outcome in antepartum hemorrhage. J Evid Based Med Healthc. 2014;1 (6):406-427. doi:10.18410/jebmh/2014/67 
5. Maurya A. Dr. Sonal Arya study of antepartum hemorrhage \& its maternal \& perinatal outcome. Int J Sci Res. 2014;4(2):2250-3153.

6. Chufamo N, Segni H, Alemayehu YK. Incidence, contributing factors and outcomes of antepartum hemorrhage in Jimma University Specialized Hospital, Southwest Ethiopia. Univ J Public Health. 2015;3(4):153-159. doi:10.13189/ujph.2015.030403

7. Sakornbut E, Leeman L, Fontaine P. Management of late pregnancy bleeding. Am Fam Physicians. 2016;75(8):1199-1206.

8. Wolfson J. Obstetric haemorrhage in Gimbie, Ethiopia. Obstet Gynaecol. 2007;9:121-126. doi:10.1576/toag.9.2.121.27314

9. Sakornbut E, Leeman L, Fontaine P. Late pregnancy bleeding. Am Fam Physician. 2007;75(8):1199-1206.
10. Women KEMHf. Antepartum haemorrhage (APH) clinical guidelines: obstetrics \& midwifery. Obstet Gynecol. 2015;2(3):1-2.

11. Naheed Rahim TR, Ara A. Risk factors associated with major placenta previa. J Med Sci. 2014;22(2):62.

12. Ghaheh HSFA, Mousavi M, Sohrabi D, Mesghari L, Mesghari L, Hosseini Z. Risk factors of placental abruption. J Res Med Sci. 2013;18:422-426.

13. Prochazka MLM, Slavik L, Hrachovec P. Selected pregnancy variables in women with placental abruption. Biomed Pap Med. 2006;150 (2):271-273. doi:10.5507/bp.2006.040

\section{Publish your work in this journal}

The Journal of Multidisciplinary Healthcare is an international, peerreviewed open-access journal that aims to represent and publish research in healthcare areas delivered by practitioners of different disciplines. This includes studies and reviews conducted by multidisciplinary teams as well as research which evaluates the results or conduct of such teams or healthcare processes in general. The journal covers a very wide range of areas and welcomes submissions from practitioners at all levels, from all over the world. The manuscript management system is completely online and includes a very quick and fair peer-review system. Visit http://www.dovepress.com/testimonials. php to read real quotes from published authors. 